\title{
ANALISA PENGEMBANGAN SISTEM INFORMASI LAYANAN E-STATEMENT (SEBUAH PENDEKATAN STUDI KASUS DI BANK XYZ)
}

\author{
Ikrar Adinata Arin \\ Program Sistem Informasi, Program Studi Sistem Informasi, Universitas Bina Nusantara \\ Jln. K.H. Syahdan No. 9, Palmerah, Jakarta Barat, 11480 \\ Telp. (021) 5345830 \\ E-mail: ikrar@binus.ac.id
}

\begin{abstract}
ABSTRAKSI
Penelitian ini bertujuan untuk memberikan solusi atas permasalahan yang hampir kebanyakan dihadapi oleh nasabah sebuah bank yaitu untuk keterlambatan Lembar Tagihan Transaksi yang diterima setiap bulannya. Belakangan semakin marak produk tabungan menggunakan e-statement, kita ambil contoh CIMB Niaga AirAsia Saver, Simas Lion Ticket, atau PermataMe bank permata. Kehadiran mereka seperti mempertegas bahwa kini zamannya serba elektronik. Lebih dari itu, ini juga sebagai upaya perbankan menerapkan green-banking di institusinya. Penelitian ini menggunakan metode Analisis Object-Oriented Analysis and Design (OOAD), dan hasil diterapkannya sistem layanan e-statement (electronic statement) pada Bank XYZ. Hasil dari analisis dan perancangan sistem informasi layanan e-statement ini diharapkan Bank $X Y Z$ dapat memiliki sistem yang dapat mengirimkan laporan transaksi apapun dapat di lihat dalam satu dokumen itu. Setoran, tarik tunai di atm, transfer antar rekening bank, pembelian ke mana, bunga bank dll. Bandingkan jika menggunakan passbook, semua transaksi yang pernah kita lakukan hanya bisa dilihat jika mencetak buku tabungan. Apabila tidak mencetak dalam periode tertentu, maka hanya akan terlihat hanya total kredit dan debet saja selama periode itu.
\end{abstract}

Kata Kunci: Pengembangan Sistem, Sistem Informasi e-Statement, e-Statement 


\section{PENDAHULUAN}

Pada masa dewasa ini, pengiriman tagihan seperti tagihan kartu credit, tagihan listrik (PLN), tagihan air (PAM), dan tagihan lainnya masih menggunakan jasa kurir (via pos) atau dapat disebut sebagai sistem manual karena tagihan masih menggunakan kertas tagihan yang dihasilkan oleh sistem dan diberikan kepada kurir untuk diantarkan ke alamat tagihan. Lamanya pengiriman pun ada yang dalam beberapa hari saja sejak akhir bulan pemakaian dan bahkan ada tagihan yang tidak sampai ke pelanggan. Akibatnya pelanggan yang tidak mendapat tagihan pun lupa membayar karena tidak mendapat kiriman tagihan dan berdampak pelanggan dikenakan sanksi berupa denda ataupun sanksi lainnya. Pengiriman tagihan ini menggunakan sangat banyak kertas dan dengan banyaknya pelanggan serta banyaknya tagihan yang diterima setiap pelanggan untuk setiap bulannya.

Cara pengiriman tagihan lainnya adalah pengiriman tagihan dalam bentuk email. Tetapi masih sedikit perusahaan yang menggunakan email untuk mengirimkan tagihan kepada pelanggan dikarenakan alasan kearnanan ataupun masalah dimana pelanggan melakukan komplain bahwa pelanggan tidak menerima tagihan berupa email padahal perusahaan sudah melakukan pengiriman.

Di dunia perbankan, tagihan yang dikirimkan ke nasabah tentunya berisikan data dan informasi yang rekening yang sangat pribadi dan rahasia (misalnya pembayaran loan, pembayaran gaji, autodebit tagihan, dll) maka bank wajib menyediakan password khusus yang hanya dihasilkan oleh sistem, sehingga password tersebut sulit untuk ditebak atau diterka orang lain. Dengan password yang dihasilkan oleh sistem, maka keamanan \& kerahasiaan informasi transaksi nasabah akan lebih maksimal.

Penerapan sistem informasi layanan e-statement pada Bank XYZ untuk membantu perusahanan dalam menyediakan $e$-statement langsung tersedia dengan cara meregistrasikan nomor rekening dan informasi diri seperti email address dari masing-masing nasabah pada portal online banking Bank XYZ. e-statement dikirimkan lewat email dalam format secured PDF sebagai keamanan tambahan. Disamping itu, akses $e$ statement nasabah hingga 7 tahun ke belakang akan tetap disimpan dengan aman dan di-download dalam format PDF.

Sistem informasi layanan e-statement yang disediakan oleh Bank XYZ untuk lembaran transaksi berikut:

- Consolidated Statement

- Current Account
- $\quad$ Foreign Currency Current Account

- Savings Account

- EcoSave Account

- $\quad$ Fixed Deposit

- $\quad$ Foreign Currency Fixed Deposit

- Loan

- Wealth Management

- Credit Card, and

- Mutual Fund

Otoritas Jasa Keuangan (OJK) pada hari Kamis, 24 April 2014 telah merilis Surat Edaran OJK Nomor 7 / SEOJK.04 / 2014 tentang pelaksanaan pertemuan tatap muka untuk penerimaan pemegang reksa dana melalui pembukaan rekening secara elektronik dan prosedur berlangganan dan penebusan reksadana oleh sistem elektronik. Surat edaran ini mengatur bahwa bank kustodian khusus untuk secara khusus memenuhi penggunaan sistem pengiriman elektronik.

Dinyatakan dalam ketentuan umum, Pasal 17c, Bank Kustodian yang mengelola langganan dan penebusan reksa dana harus dapat mengirim laporan konfirmasi secara elektronik melalui email ke unit pemegang reksa dana. Peraturan baru ini dimaksudkan untuk memfasilitasi promosi investasi reksadana dan layanan ini sudah lama ditunggu oleh manajer investasi dan pelanggan.

Sistem informasi layanan $e$-statement ini akan dibangun menggunakan basis web (web-based) dan dapat dipergunakan oleh Operasional User di Bank.

\section{RUANG LINGKUP}

Ruang lingkup merupakan sebuah batasan pembahasan yang menentukan seluas dan sedalam apa pembahasan dalam sebuah penelitian, dan berfungsi juga membantu mempermudah penelitian, agar pembahasan penelitian menjadi terfokus. Ruang lingkup pada penelitian ini sebagai berikut:

a. Menganalisis permasalahan yang dihadapi oleh User Operasional Bank XYZ dan merincikan keinginan dari mereka untuk kehadiran sebuah sistem layanan yang memberikan kemudahan dalam mengirimkan lembaran tagihan transaksi ke nasabah

b. Membuat desain dari seluruh dokumentasi yang telah dibuat kedalam sebuah sistem.

\section{METODE PENELITIAN}

Metodologi yang digunakan dalam penelitian ini adalah sebagai berikut :

1. Studi Pustaka 
Mengumpulkan data dan informasi dengan cara mencari referensi mengenai analisis dan perancangan suatu web aplikasi melalui internet, jurnal, buku-buku, dan artikel yang menyediakan informasi yang dibutuhkan dalam penelitian ini.

\section{Studi Lapangan}

Metode yang digunakan dalam studi lapangan terdiri atas 3 (tiga) cara, yaitu:

a. Wawancara

Wawancara dilakukan secara langsung dengan Head of Operation Transfer Agency PT. Bank XYZ. Wawancara tersebut dilakukan guna untuk mengetahui proses bisnis yang sedang berjalan terkait dengan bagaimana lembaran tagihan transaksi yang dikirimkan ke nasabah, masalah yang dihadapi, dan harapan perusahaan akan pengembangan sistem ini bagi perusahaan.

Tujuan bisnis adalah untuk dapat menghasilkan dan mengirimkan e-statement untuk laporan rekening dan laporan konfirmasi nasabah sesuai persyaratan dan peraturan.

b. Dokumentasi

Dokumentasi dilakukan dengan cara menelusuri bukti fisik yang terkait dengan lembaran tagihan transaksi berupa hardcopy.

c. Dokumen Sampling

Mempelajari dokumen-dokumen yang diberikan oleh tim pengembang sistem layanan e-statement, untuk kemudian dianalisis menjadi basis data yang diperlukan dalam perancangan aplikasi e-statement

3. Metode Analisis dan Perancangan

Menurut (Naresh Kumar, 2013) terdapat 9 tahapan di dalam metode prototyping. Dari 9 tahapan yang ada di dalam metode prototyping kami hanya melakukan 5 tahap, diantaranya sebagai berikut:

a. Analisis

Membuat aktivitas sistem yang berupa:

- Activity Diagram

- Use case diagram

- Use case description

- Class diagram

- System sequence diagram

- User Interface

b. Desain

Membuat desain kasar untuk web e-statement agar memudahkan pada saat membuat prototipe

c. Prototipe

Membuat prototipe dari hasil desain kasar yang telah dibuat sebelumnya

d. Evaluasi User

Melakukan evaluasi dari prototipe yang telah dibuat

e. Revisi dan update

Memperbaiki kesalahan yang ditemukan pada saat evaluasi dengan pelanggan

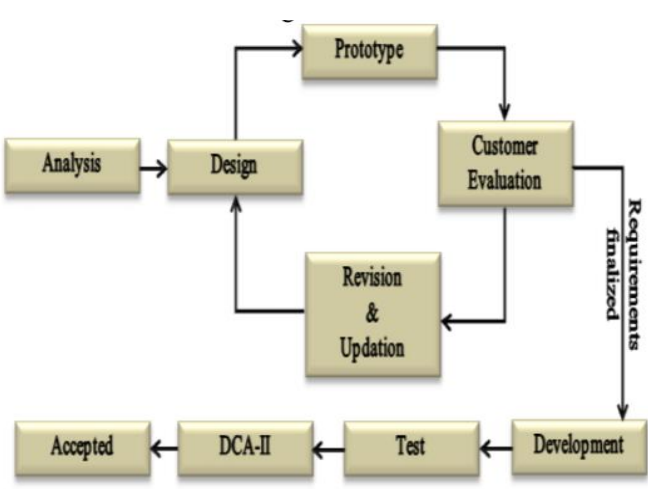

Gambar 1. Model System Development Life Cycle

Sumber : Naresh Kumar, A. S. (2013). Evolving a New Software Development Life. Evolving a New Software Development Life Cycle Model SDLC - 2013 with Client Statisfaction, 5.

\section{HASIL DAN DISKUSI}

Upaya pengiriman hardcopy ke setiap nasabah untuk lembaran tagihan transaksi bukanlah hal mudah dan cepat. Dibawah ini adalah perbandingan yang memperlihatkan keuntungan dalam penggunaan mekanisma e-delivery dan hardcopy delivery diperoleh dari requirement document yang disampaikan oleh User/Bisnis.

Tabel 1 : Perbandingan hardcopy delivery dan e-delivery

\begin{tabular}{|c|c|c|}
\hline Scenario & $\begin{array}{l}\text { Hardcopy } \\
\text { Delivery }\end{array}$ & E-Delivery \\
\hline $\begin{array}{l}\text { Storing } \\
\text { letterheads } \\
\text { from Fund } \\
\text { Managers }\end{array}$ & $\begin{array}{l}\text { Requires storage } \\
\text { room, transport costs } \\
\text { to pick up the papers } \\
\text { and FTE time to } \\
\text { arrange the } \\
\text { safekeeping }\end{array}$ & - \\
\hline $\begin{array}{l}\text { Management } \\
\text { of Invoice \& } \\
\text { Receipts }\end{array}$ & $\begin{array}{l}\text { Large number of } \\
\text { airway bills and } \\
\text { courier invoices } \\
\text { which have to be } \\
\text { sorted, safe kept, and } \\
\text { managed. }\end{array}$ & $\begin{array}{l}\text { All confirmations are stored and } \\
\text { monitored electronically }\end{array}$ \\
\hline $\begin{array}{l}\text { Delivery } \\
\text { Process }\end{array}$ & $\begin{array}{l}\text { Higher chance of } \\
\text { delivery failure. } \\
\text { Points of failure } \\
\text { include: } \\
\text { - Wrong address } \\
\text { - Delivery } \\
\text { mistakes by the } \\
\text { courier } \\
\text { - Delivered to } \\
\text { people other } \\
\text { than the } \\
\text { intended } \\
\text { recipient }\end{array}$ & $\begin{array}{l}\text { Lower chance of delivery failure } \\
\text { as long as email is registered } \\
\text { correctly. } \\
\text { Will directly be received by the } \\
\text { intended recipient. }\end{array}$ \\
\hline \begin{tabular}{|l} 
Delivery \\
failure \\
correction \\
(Could be \\
caused by \\
wrong \\
registered \\
address, \\
delivery \\
errors \\
/courier, etc.)
\end{tabular} & $\begin{array}{l}\text { Requires FTE effort } \\
\text { to check the airway } \\
\text { bill, contact the } \\
\text { delivery vendor, } \\
\text { receive the recipient's } \\
\text { name, confirm it with } \\
\text { client, and finally } \\
\text { redeliver the } \\
\text { statements } \\
\text { Waiting for the } \\
\text { delivery vendor to get } \\
\text { back, and redelivering }\end{array}$ & $\begin{array}{l}\text { Efforts are limited to checking } \\
\text { the registered email, then } \\
\text { resending/reconfirming/changing } \\
\text { the registered email } \\
\text { Requiring a relatively lower } \\
\text { rechecking and redelivery time }\end{array}$ \\
\hline
\end{tabular}




\begin{tabular}{|l|l|l|}
\hline & $\begin{array}{l}\text { the statements would } \\
\text { certainly take some } \\
\text { time and effort }\end{array}$ & \\
\hline
\end{tabular}

Merupakan persyaratan peraturan bahwa bank perlu mengirim pernyataan kepada pelanggan untuk tujuan rekonsiliasi. Aplikasi akan mengirimkan pernyataan kepada pelanggan melalui email seperti digambarkan:

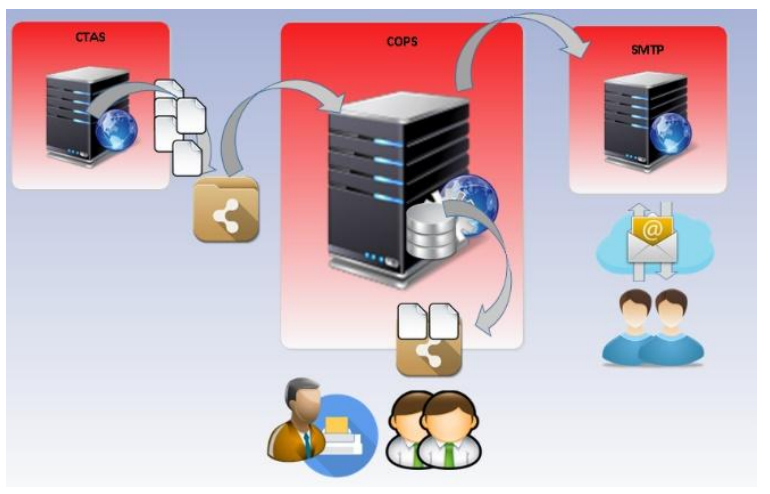

Gambar 2. Flow process diagram

Keterangan Gambar :

1. Dashboard Module

Modul ini memberikan informasi ringkasan permintaan proses proses persetujuan yang harus dilakukan oleh pemeriksa.

2. Audit Trail/User Log

Modul ini memberikan informasi kegiatan pengguna dalam aplikasi ini.

3. Preference/System Parameter

Modul ini memberikan informasi dan memungkinkan untuk mengelola parameter yang digunakan oleh aplikasi.

4. Master

Modul ini memberikan referensi informasi untuk modul yang lain.

Product

Modul ini memberikan informasi dan memungkinkan untuk mengelola produk master

Selling Agent

Modul ini memberikan informasi dan memungkinkan untuk mengelola agen penjualan utama

Fund Manager

Modul ini memberikan informasi dan memungkinkan untuk mengelola manajer dana master.

5. Upload File

Modul ini menyediakan fitur untuk mengunggah file untuk diproses oleh layanan.

6. Statement Setup

Modul ini memberikan informasi dan memungkinkan untuk mengelola proses pengiriman email pernyataan persiapan.

\section{Email Template}

Modul ini memberikan informasi dan memungkinkan untuk mengelola template email untuk pengiriman email pernyataan.

Statement Logo

Modul ini menyediakan informasi dan memungkinkan untuk mengelola gambar / logo untuk logo header pernyataan PDF.

7. Adhoc Statement

Modul ini menyediakan fitur untuk mengirim ulang pernyataan elektronik yang telah dikirim.

8. Approval Log

Modul ini menyediakan informasi permintaan untuk persetujuan dan proses persetujuan riwayat.

Approval system parameter.

Modul ini memberikan informasi dan memungkinkan pemeriksa untuk melakukan proses persetujuan.

Approval master product.

Modul ini memberikan informasi dan memungkinkan pemeriksa untuk melakukan proses persetujuan.

Approval master selling agent.

Modul ini memberikan informasi dan memungkinkan pemeriksa untuk melakukan proses persetujuan.

Approval master fund manager.

Modul ini memberikan informasi dan memungkinkan pemeriksa untuk melakukan proses persetujuan.

Approval email template.

Modul ini memberikan informasi dan memungkinkan pemeriksa untuk melakukan proses persetujuan.

Approval statement logo.

Modul ini memberikan informasi dan memungkinkan pemeriksa untuk melakukan proses persetujuan.

9. Report

Modul ini menyediakan informasi transaksi / pernyataan log yang diproses.

10. Background Process/Windows Service Raw Statement Processing

Proses ini akan menangani input file yang ada setiap hari dan pernyataan bulanan (file TXT). Proses ini juga akan membuat pernyataan PDF massal dan pemisahan XML berdasarkan pernyataan tata letak harian dan bulanan.

\section{Statement Splitting}

Proses ini akan membagi Pernyataan PDF setiap hari dan pernyataan bulanan. Proses ini juga akan membuat file impor XML untuk Layanan Impor File

File Importing

Proses ini akan menangani pernyataan

file keberadaan dari keluaran Layanan 
Pemisahan Pernyataan dan profil pelanggan. Proses ini juga akan mengimpor file impor XML ke dalam basis data dan menempatkan pernyataan file PDF mentah.

Statement PDF Processing

Proses ini akan menyiapkan / mendaftarkan pernyataan untuk menjadwalkan pengiriman layanan pengiriman email dengan alamat email terdaftar dan enkripsi file PDF pernyataan non-perusahaan.

Schedule Email Sending

Layanan ini akan mengirimkan pernyataan reguler.

\section{TXT Hardcopy Generating}

Layanan ini akan menghasilkan file teks (hardcopy untuk vendor pencetakan) dari pernyataan yang gagal mengirim email melalui layanan pengiriman email.

\section{Email Delivery Report Generating} Proses ini akan menghasilkan file TXT status terbaru dari setiap pernyataan (laporan harian dan bulanan) setiap hari. Email Delivery Tracking

Layanan ini akan melakukan tracking untuk status pengiriman e-statement ke nasabah

Non Schedule Email Sending

Layanan ini akan melakukan pengiriman e-statement ad-hoc jika ada permintaan pengiriman dari nasabah Generate Hardcopy

Layanan ini untuk memisahkan tipe tagihan / statement nasabah yang harus dicetak dalam bentuk hardcopy

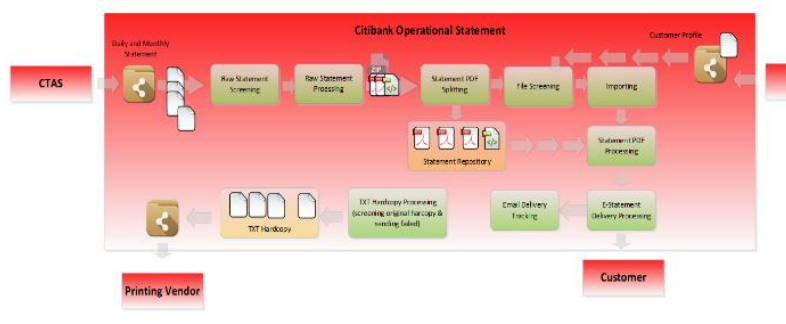

Gambar 3. E-Statement Flow Diagram

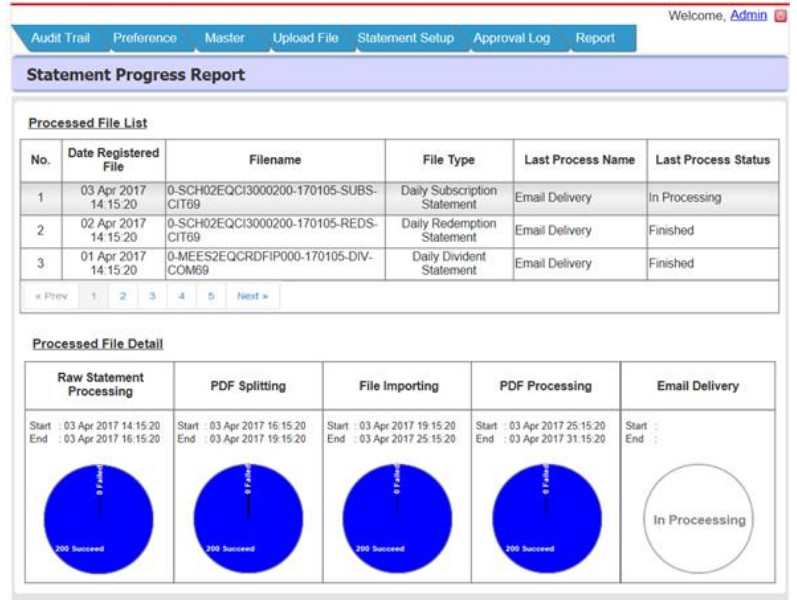

Gambar 4. E-Statement Progress Dashboard

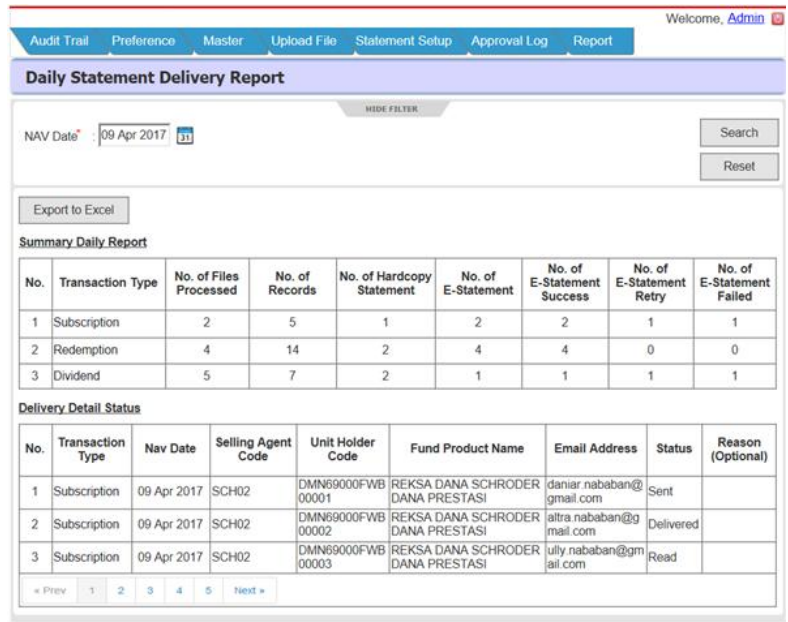

Gambar 5. Daily Statement Delivery Report

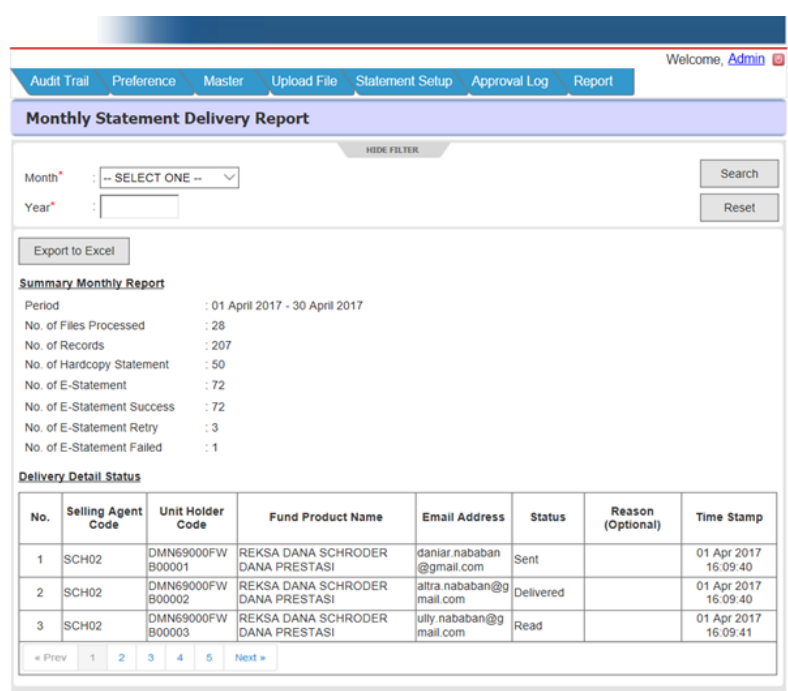

Gambar 6. Monthly Statement Delivery Report

User Interface Design 


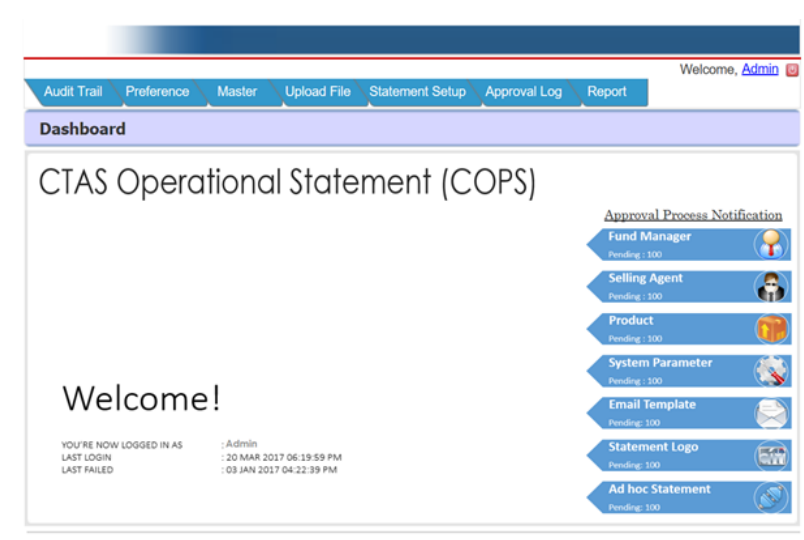

Gambar 7 : E-Statement System Bank Xyz

\section{KESIMPULAN}

Dengan merancang sistem layanan $e$-statement ini diharapkan dapat mengatasi permasalahan yang terjadi pada sistem percetakan lembaran tagihan transaksi nasabah yang masih manual yang digunakan saat ini, sehingga waktu kerja diharapkan dapat terdokumentasi secara akurat dan meningkatkan waktu pengerjaan dan pengendalian proses internal disisi Operasional User. Layanan e-statement ini menerima laporan aktifitas perbankan dan transaksi baik secara harian (daily) atau bulanan (monthly) melalui email dengan lebih nyaman, cepat dan aman, sekaligus turut serta dalam usaha mempertahankan kelestarian hutan. Informasi yang terdapat pada lembaran tagihan transaksi telah dilindungi dengan password dan pengiriman melalui email dilindungi dengan 128-bit enkripsi dengan kombinasi password.

\section{DAFTAR PUSTAKA}

Kumar, Naresh, A. S. Zadgaonkar, Abhinav Shukla. (2013). Evolving a New Software Development Life Cycle Model SDLC-2013 with Client Satisfaction. India: m Dr. C. V. Raman University Project Documentation. (2018). Business Requirement Document Jakarta, Bank XYZ.

Press Release: Issuance of OJK Circular Letter Number 7/SEOJK.04/2014. OJK Circular Letter Number 7/SEOJK.04/2014

Satzinger, J.W., Jacson, R.B., \& Burd, S.D. (2005). Object-Oriented Analysis and Design with the Unified Process. (4th Edition). Oston: Course Technology, Cengage Learning.

Whitten, Jeffrey L., Bentley, Lonie D. (2007). System Analysis and Design Methods. (7th Edition). New York: Mc Graw-Hill 